Preference is given to letters commenting on contributions published recently in the JRSM. They should not exceed 300 words and should be typed double spaced

\section{Patient-centred care after Shipman}

Professor Baker (April $2004 J R S M^{1}$ ) believes that the Shipman case exposed a medical culture in need of radical reform. In laying blame on the medical profession he tends to ignore those who were primarily responsible for delay in detecting Shipman's murderous behaviour.

We now know that Shipman was a criminal who at the same time was a registered medical practitioner. It was in the public domain that Shipman had a criminal record dating back to his time in practice in Todmorden, West Yorkshire. Following his disgrace and his rehabilitation, he applied to enter practice in Hyde, Cheshire. His new family practitioner committee failed to check whether he had had a previous criminal record.

During Shipman's time in practice in Hyde, the family practitioner committee had medical advisors visiting practices, and part of the advisors' duties was to check doctors' drug registers. Pharmaceutical inspectors visited chemist outlets regularly and likewise examined drug registers.

In both of Shipman's convictions, any failure in either the storage of drugs or the recording of drugs in drug registers had to be the responsibility of Government inspectors to enforce regulations available to them at the time or to detect irregularities in their system. What information was passed by all of those professional Statepaid inspectors to alert the appropriate authorities with regard to Shipman's activities? Our coroners were not vigilant. Thus they failed in their duties. The police, though alerted, failed to investigate fully a complaint. Funeral directors also had a public duty. Government statistical analysts through their computerized information should have noticed an abnormal trend. Yet Professor Baker writes about systems that failed at the patient-doctor level and at the patient-professional level.

It is true that there was and is a system failure in death certification. The medical profession, the Royal Colleges, the BMA and the General Medical Council collectively and separately over the years lobbied for changes in death certification. As a profession we recognized that technology has progressed and changes were needed in many areas. Government must accept that funding is a vital element so that our monitoring systems can be upgraded. Government had failed to provide Parliamentary time to support requests from the General Medical Council and the Royal Colleges for new statutory regulations.

It was Government-paid officials who failed the people of Hyde. The statutory instruments that were available to them were not used.

\section{E Tierney}

Birch House, Broadley, Whitworth, Rochdale OL12 8RU, UK

\section{REFERENCE}

1 Baker R. Patient-centred care after Shipman. J R Soc Med 2004;97:161-5

\section{Feeling cold after donepezil}

We have seen four patients who reported feeling cold within a few weeks of starting donepezil hydrochloride for Alzheimer's disease. On investigation, their temperatures and peripheral circulations were within normal limits. Their Mini Mental State Examination scores at the start of treatment ranged from $13 / 30$ to $22 / 30$ and the medical histories included (1) epilepsy; (2) hypertension, polymyalgia rheumatica, osteoporosis; (3) transient ischaemic attack, varicose veins, pneumoconiosis; (4) sigmoid diverticular disease, respectively. None had previously reported disturbed temperature perception. Because of this symptom, which began within 8 weeks of starting donepezil, the patients kept their rooms very warm; one patient set the thermostat to $24{ }^{\circ} \mathrm{C}$. Discontinuation of the medication alleviated symptoms in two patients; one died from unrelated causes; and the other decided to tolerate the symptom in view of the benefits derived from donepezil.

A search of Psyclit, Embase, Medline, CINAHL and ACP Journal Club yielded no reports of such a side-effect from donepezil or other cholinergic agents. Nor was it seen in acute pyridostigmine poisoning. ${ }^{1}$ In healthy volunteers eptastigmine, a new acetylcholinesterase inhibitor, may have a weak effect on (lowering) body temperature. ${ }^{2}$

Although Alzheimer's disease may involve the suprachiasmatic nucleus of the hypothalamus, and thus potentially affect circadian and bodily temperature rhythms, ${ }^{3}$ there are no previous reports of changes in self-awareness of temperature in this condition. Temperature disturbances of this sort, although not life-threatening, can be uncomfortable and also costly in extra heating. The possible drug causation deserves systematic assessment. Meanwhile, carers should be particularly sympathetic to patients with Alzheimer's disease when they complain of feeling cold.

\section{Subha Thiyagesh}

\section{Claire Young ${ }^{1}$}

Sean Spence ${ }^{2}$

${ }^{1}$ Sheffield Care Trust and ${ }^{2}$ University of Sheffield, Sheffield, UK Correspondence to: Dr Subha Thiyagesh, The Longley Centre, Norwood Grange Drive, Sheffield S5 7JT, UK

E-mail: s.thiyagesh@sheffield.ac.uk

\section{REFERENCES}

1 Almog S, Winkler E, Amitai Y, et al. Acute pyridostigmine overdose: a report of nine cases. Isr J Med Sci 1991;27:659-63

2 Mant T, Troetel WM, Imbimbo BP. Maximum tolerated dose and pharmacodynamics of eptastigmine in elderly healthy volunteers. J Clin Pharmacol 1998;38:610-17 
3 Stopa EG, Volicer L, Kuo-Leblanc V, et al. Pathological evaluation of the human suprachiasmatic nucleus in severe dementia. J Neuropathol Exp Neurol 1999;58:29-39

\section{Language and brain injury}

In the patient described by Dr Coughlan and her colleagues (May $2004 J R S M^{1}$ ) the French accent that developed after a stroke turned out to be a disturbance of native speech patterns. I was reminded, however, of a case of head injury in which several languages were lost and serially regained. On a visit to London the patient, a Belgian who lived in Greece and was fluent in many languages, looked the wrong way and was knocked over by a passing car. For three days her whereabouts were unknown, and the Belgian Embassy eventually traced her to the National Hospital, Queen Square. It emerged that, on admission to the hospital, she had spoken a language that no-one recognized. This was Flemish. As she improved, she reacquired English and later Greek. She made a full recovery from the head injury, and the languages returned in the order she had learnt them.

\section{Grant Williams}

35 Wimpole Street,

London W1G 8GY, UK

\section{REFERENCE}

1 Coughlan T, Lawson S, O’Neill D. French without tears? Foreign accent syndrome. J R Soc Med 2004;97:242-3

\section{Treatment of age-related macular degeneration}

The pattern of the retinal vasculature is thought to be unique for each eye. In the excellent review article by $\mathrm{Mr}$ Browning and co-authors (April $2004 J R S M^{1}$ ) it was therefore interesting to see how this pattern changed after photodynamic therapy (their Figure $3 a$ and $b$ ). Verteporfin photodynamic therapy is clearly powerful medicine!

\section{David L Boase}

Eye Department, Queen Alexandra Hospital, Cosham, Portsmouth PO6 3LY, UK

\section{REFERENCE}

1 Browning AC, Amoaku WM, Dua HS. Treatment of age-related macular degeneration. J R Soc Med 2004;97:166-9

\section{Author's reply}

Mr Boase, with his keen eye, has spotted an embarrassing mistake. Through a filing error the angiograms supplied for Figure 3 were indeed from different patients, though $3 b$ does have the desired property of illustrating closure of the neovascular membrane three months after therapy.

\section{Andrew C Browning}

\section{A cluster of deaths by footwear, 1894-1900}

When the 1837 Act for Registering Births, Deaths and Marriages established national registers, the first priority of the Registrar General and of his Superintendent Registrar, Dr William Farr, was to ensure the comprehensiveness of the 940000 events registered each year. Conscious of the prevalence of idiosyncratic diagnoses of the causes of death, and of the potential value of comparing patterns in different populations, Farr led a campaign for the international standardization of causes of death according to modern medical concepts, to which we owe the International Classification of Diseases.

Despite the best educational efforts of the Registrars General, their annual reports for England, 1863-1911, included, 'sting by a blue bottle', 'bite of a leech', 'bite of a child' and 'Indian corn blown in ear', as registered causes of death. The brief period 1894 to 1900 saw a remarkable cluster of 28 deaths reported as having been caused by boots. 'Tight boots' was given as cause of death for 4 females, ages 35-64, and for 18 males, ages 1-84, while 'chaffing boot' killed one female in the age group 5-9 years. 'Injury by boot' accounted for the deaths of 4 females in the age range 4-64, 'rubbing by boot' the death of 1 female in the age group 15-19. Neither in the preceeding years 1863 to 1894 , nor in subsequent years 1900 to 1911 , was the boot mentioned as causal agent.

The Registrars General have noted the emergence and disappearance of certain diagnoses in their Death Register over the generations, and have accounted for these phenomena. However, it is not evident how, by applying the underlying principles, one might account for the time cluster of boot-associated deaths. The contemporary authors Gissing, Wells and Collins, though their booted heroes and heroines trudged repeatedly across London and far out into its suburbs, provide no clues to the reasons for this mystery.

\section{Morris Greenberg}

74 North End Road, London NW11 7SY, UK

E-mail: gmgreenberg@macunlimited.net

\section{Medically unexplained symptoms}

Professor Butler and colleagues propose an approach whereby both patients and clinicians can regard 'medically unexplained symptoms' as unambiguously medical (May $\left.2004 J_{R S M}^{1}\right)$.

As a clinician I found myself wondering how this new formulation of medically unexplained symptoms would actually help in my clinical work where I see a significant number of such patients. In contrast to the authors' assertion that clinicians are required 'to do an awkward dance of collusion with the patient' I find that a rational 
understandable discussion of the ways in which normal sensations are modified on a continuous basis by the brain (e.g. the perception of touch that changes when the ring is moved from its usual finger to a different finger) or the effects of the brain on somatic symptoms (e.g. stage fright causing vomiting and diarrhoea) a remarkably powerful and intuitively useful explanation to the patient. I then go on to explain that this process occurs in the subconscious mind which is not amenable to reason or voluntary control. The only way to deal with these symptoms is to train, rather than persuade, the subconscious mind to behave differently.

I am at a loss to see how bringing in another dimension-i.e. that their symptom is somehow due to their 'reaction to the world' - helps, or how this assists patients to see their problems as unambiguously medical. Nevertheless an enjoyable and challenging article.

\section{John Tripp}

Department of Child Health, Peninsula Medical School, Church Lane, Heavitree, Exeter EX2 5SQ, UK

E-mail: jhtripp@ex.ac.uk

\section{REFERENCE}

1 Butler CC, Evans M, Greaves D, Simpson S. Medically unexplained symptoms: the biopsychosocial model found wanting. $J$ R Soc Med 2004;97:219-22

\section{Practice made perfect}

The comprehensive demolition of the fantasy of clinical freedom in the May issue of the JRSM ${ }^{1}$ is in danger of letting in another by the back door, the fantasy of the unblemished career. In reality only unblemished records exist.

Serious blemishes undeniably need serious medical attention, otherwise the putative benefits of belonging to a profession will vanish. Current appraisal however is comparable to selecting teenagers by the number of their spots. Cosmetic efforts to excise, explain or erase these often nominal blemishes take up more and more of less time, better spent on practical work.

The only case for this new fantasy and the dubious legality which promotes it would seem to be a period of involuntary work for all concerned, whatever their acronyms, in the other two-thirds of the world.

\section{H M C Corfield}

The Old Parsonage Barn, Barn Street, Crewkerne, Somerset TA18 8BP, UK

\section{REFERENCE}

1 Samanta A, Samanta J. Reputation of the medical profession: fantasy, reality and legality. J R Soc Med 2004;97:211-17

\section{Ophthalmic surgical training}

We respond to Richard Smith's observations (June 2004 $J R S M$ ) in relation to our study ${ }^{1}$ of surgical training amongst ophthalmic senior house officers (SHOs). At the outset, we too expected SHOs in district general hospitals (DGHs) to gain more surgical experience than those in teaching hospitals but found that the proportion of year 3 and 4 SHOs that met the College requirement to be achieved by the end of year 2 (50 completed phako operations) was $36.8 \%$ in DGHs and $46.4 \%$ in teaching hospitals. Our cross-sectional survey does not allow us to test his suggestion that SHOs in teaching hospitals perform more phako procedures because they have more surgical experience. However, our data do show that, amongst SHOs in their second year of training, those in a teaching hospital perform more phako procedures per week than those in a DGH. This is most striking when gender is taken into account: the year-2 woman SHO in a DGH fares very badly compared with her male counterpart in a teaching hospital - mean number of phakos performed per week 0.44 and 1.20, respectively. Most year-1 SHOs do work in a DGH (96 of 112 respondents), but we are unable to comment on how they move from the DGH to teaching hospital. Richard Smith's suggestion that teaching hospitals somehow manage to cream off a surgically-elite group of SHOs in the second year is intriguing.

No doubt there are a number of ways of ensuring that a trainee surgeon's surgical experience is protected, and Richard Smith offers one simple method of quantifying this. With the anticipated reduction in time for surgical training this is an important debate, ${ }^{2}$ and one that is justifiably attracting considerable attention in the medical press. $^{3}$

\section{Alistair R Fielder ${ }^{1}$ \\ Philip Murray ${ }^{2}$ \\ Andrew Gibson ${ }^{3}$ \\ Martin Watson ${ }^{4}$ \\ Merrick Moseley ${ }^{1}$ \\ Mary Boulton ${ }^{5}$ \\ ${ }^{1}$ Department of Visual Neuroscience, Imperial College London, Room 9L02, Charing Cross Campus, St Dunstan's Road, London, W6 8RP; ${ }^{2}$ University of Birmingham; ${ }^{3}$ Oxford Radcliffe Hospital; ${ }^{4}$ Imperial College; ${ }^{5}$ Oxford Brookes University, UK \\ E-mail: a.fielder@imperial.ac.uk}

\section{REFERENCES}

1 Watson MP, Boulton MG, Gibson A, Murray PI, Moseley MJ, Fielder AR. The state of basic surgical training in the UK: ophthalmology as a case example. $J$ R Soc Med 2004;97:174-8

2 Chikwe J, de Souza AC, Pepper JR. No time to train the surgeons. BMJ 2004;328:418-19

3 Letters (various). No time to train surgeons. BMJ 2004;328:1133-5

\section{Preoperative radiotherapy for rectal cancer}

In their prospective audit of waiting times for the treatment of rectal cancer (March $2004 J R S M^{1}$ ) Sarah Duff and her colleagues state that pre-operative short-course radiotherapy (SRT, 4 days $\times 5 \mathrm{~Gy}$ ) for rectal cancer reduces the risk of local recurrence and may translate into improved 
patient survival. However, much of the evidence for this benefit comes from the Swedish Rectal Cancer Trial which showed a relative survival benefit of $21 \%$ and an increase in the 5 -year survival from $48 \%$ to $58 \%$ with a reduction of local recurrence from $27 \%$ to $11 \% .^{2}$ This would suggest that the benefits of adjuvant radiotherapy are dependent on a high local recurrence rate for surgery alone. With local recurrence rates of less than $10 \%$ there are no data demonstrating a beneficial effect with the addition of radiotherapy. ${ }^{3}$

Whilst local recurrence decreased from $8.2 \%$ to $2.4 \%$ after a median follow up of 2 years, the surgery-alone arm in the recent Dutch TME and SRT Trial had an unacceptably high local recurrence rate, especially as only mobile tumours were recruited. These data imply a background of oncologically inadequate surgery in a substantial proportion of patients. ${ }^{4}$ Despite attempts to 'standardize' surgery, by workshops and live demonstrations, 24\% of specimens did not reach the required TME grade (Quirke grade 1 or 2), on account of violation of the fascial envelope, incision or tearing into the mesorectum and irregularities of the surface. Thus any SRT effect becomes inconclusive because of poor quality TME specimens. Furthermore, only curative resections were considered and no universal pretreatment staging system was used. Finally, though benefit from SRT was demonstrated in some patients for local recurrence, no effect was seen on survival out to 5 years (van de Velde C, personal communication). Predicted local recurrence in the Dutch TME Trial at 5 years would be 16-23\% for surgery alone on high-risk rectal carcinoma if $55-80 \%$ of all local recurrences were observed during the first 2 years. ${ }^{5}$

Total mesorectal excision has been demonstrated to achieve a local recurrence rate of $6 \%$ at 5 years and $8 \%$ at 10 years, for rectal cancers of all stages, and 3\% at 5 years and $4 \%$ at 10 years for curative resections, in a personal series - which is unique since the percentage of patients receiving preoperative radiotherapy was only $9 \% .6$ Thus a local recurrence rate of $3 \%$ can lead to a cure rate of $80 \%$ at 5 years and $78 \%$ at 10 years.

Preoperative radiotherapy is associated with toxicity, early complications and long-term side-effects, and should be used only when it is of benefit. Radiotherapy may be indicated in rectal carcinomas invading near to, or involving, the mesorectal fascia since radiotherapy produces maximal effect on the periphery of the tumour. MRI is the most promising modality to select out cases where the surgical resection margin is threatened. The balance of evidence suggests that the survival from rectal cancer does not change with SRT, which, as currently administered, does not downstage the tumour and does not compensate for surgical positive margins. ${ }^{7}$

\author{
Gisella Salerno ${ }^{1}$ \\ Ian Daniels ${ }^{1}$ \\ Matthew Croxford ${ }^{1}$ \\ Gina Brown ${ }^{2}$ \\ R J Heald ${ }^{1}$ \\ Pelican Cancer Foundation, The Ark, North Hampshire Hospital, Aldermaston \\ Road, Basingstoke RG24 9NA; ${ }^{2}$ Radiology Department, Royal Marsden Hospital, \\ Sutton SM2 5PT, UK \\ Correspondence to: Gisella Salerno \\ E-mail: G.Salerno@pelicancancer.org
}

\section{REFERENCES}

1 Duff SE, Wood C, McCredie V, Levine E, Saunders MP, O'Dwyer ST. Waiting times for treatment of rectal cancer in North West England. $J R$ Soc Med 2004;97:117-18

2 Stockholm Colorectal Cancer Study Group. Randomized study on preoperative radiotherapy in rectal carcinoma. Ann Surg Oncol 1996;3:423-30

3 Ross A, Rusnak C, Weinerman B, et al. Recurrence and survival after surgical management of rectal cancer. Am J Surg 1999;177:392-5

4 Kapiteijn E, Marijnen CA, Nagtegaal ID, et al. Pre-operative radiotherapy combined with total mesorectal excision for resectable rectal cancer. N Engl J Med 2001;345:638-46

5 Hermanek P, Heald RJ. Pre-operative radiotherapy for rectal carcinoma? Has the case really been made for short course preoperative radiotherapy if surgical standards for rectal carcinoma are optimal? Colorectal Dis 2004;6:10-14

6 Heald RJ, Moran BJ, Ryall RD, Sexton R, MacFarlane JK. Rectal cancer: the Basingstoke experience of total mesorectal excision, 19781997. Arch Surg 1998;133:894-9

7 Marijnen CA, Nagtegaal ID, Klein Kranenbarg E, et al. No downstaging after short-term preoperative radiotherapy in rectal cancer patients. $J$ Clin Oncol 2001;19:1976-84

\section{CORRECTION}

\section{An unusual paracetamol overdose}

Through a typographical error this letter (May $2004 \mathrm{JRSM}^{1}$ ) states that $3 \mathrm{~g} \mathrm{Na}=0.130 \mathrm{mmol} \mathrm{Na}$. The latter value should be mol, not mmol.

\section{REFERENCE}

1 Adams MWJ, Chrispin P, Spice M. An unusual paracetamol overdose. J R Soc Med 2004;97:256 